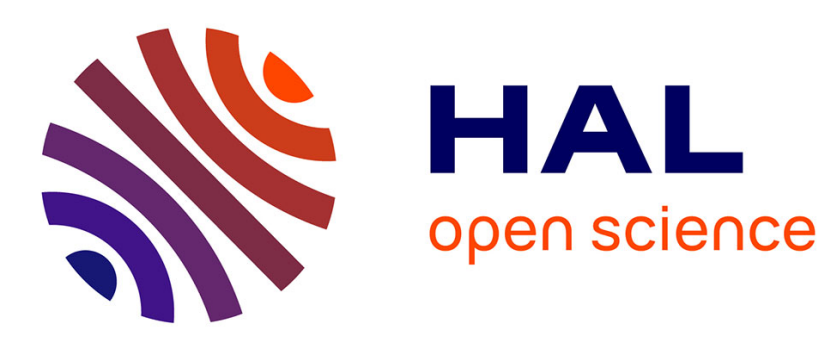

\title{
Generating precipitation ensembles for flood alert and risk management
}

\author{
A. Caseri, M.H. Ramos, P. Javelle, E. Leblois
}

\section{To cite this version:}

A. Caseri, M.H. Ramos, P. Javelle, E. Leblois. Generating precipitation ensembles for flood alert and risk management. 6th International Conference on Flood Management (ICFM6), Sep 2014, Sao Paulo, Brazil. 9 p. hal-01118905

\section{HAL Id: hal-01118905 \\ https://hal.science/hal-01118905}

Submitted on 20 Feb 2015

HAL is a multi-disciplinary open access archive for the deposit and dissemination of scientific research documents, whether they are published or not. The documents may come from teaching and research institutions in France or abroad, or from public or private research centers.
L'archive ouverte pluridisciplinaire HAL, est destinée au dépôt et à la diffusion de documents scientifiques de niveau recherche, publiés ou non, émanant des établissements d'enseignement et de recherche français ou étrangers, des laboratoires publics ou privés. 


\section{$6^{\text {TH }}$ INTERNATIONAL CONFERENCE \\ ON FLOOD TIANAGETENT}

\section{GENERATING PRECIPITATION ENSEMBLES FOR FLOOD ALERT AND RISK MANAGEMENT}

CASERI, A ${ }^{1}$, RAMOS, M.H. ${ }^{2}$, JAVELLE, P. ${ }^{1}$ and LEBLOIS, . $^{3}$

1. IRSTEA (National Research Institute of Science and Technology for Environment and Agriculture), Aix-enProvence, France

2. IRSTEA (National Research Institute of Science and Technology for Environment and Agriculture), Antony, France

3. IRSTEA (National Research Institute of Science and Technology for Environment and Agriculture), Lyon, France

ABSTRACT: Precipitation fields are crucial for hydrological forecasting. A forecasting system comprising a rainfall-runoff model uses observed and forecast precipitation to forecast discharges several hours to days ahead, which will be used for flood alert and risk management. Many sources of uncertainty play a role in a hydrological forecasting system, including uncertainties coming from the observed precipitation fields used as input data. One approach to take into account these uncertainties is to generate an ensemble of possible scenarios of observed precipitation. The aim of this study is to create an ensemble of precipitation fields merging information from rainfall radar and rain gauges. To do that, the turning bands method (TBM) adapted by Leblois and Creutin (2013) is applied in a new manner, eg with: 1) the generator parameters estimated from radar rainfall fields and 2 ) the generated fields conditioned on precipitation data measured by rain gauges. The case of a rainfall event observed in the Var region (southeastern France) is used to illustrate the method. Results show that ensemble simulation experiments conditioned on point measurements can be useful to quantify the uncertainties of precipitation fields observed by rain gauges. The proposed method could be a solution to merge radar and rain gauges information, while quantifying the observed precipitations uncertainties.

Key Words: uncertainties, precipitation ensembles, flash flood.

\section{INTRODUCTION}

Precipitation data are very important for hydrological forecasting systems operating with a rainfallrunoff model and designed to provide information on forecast discharges for flood alert and risk management. They are the major input data of many hydrological models and also represent crucial information to update hydro-meteorological conditions when forecasting river discharges in real-time.

Currently, precipitation data used in hydrological modeling and flood alert systems are usually measured by rain gauges and/or meteorological radar. The advantage of point measurements at rain gauges is their precision at the measured point in terms of precipitation amounts, while radar measurements are more appropriate to represent the spatial variability of the precipitation field (Berne and Krajewski, 2013).

Regardless of the type of measure, associated observation uncertainties are present and impact hydrological forecasts in the forecasting chain (see for instance, Uijlenhoet and Berne, 2008; Liechti et al., 2013, and references therein). Rain gauges data can have errors and uncertainties may occur due to strong winds or blocked sensors, for instance. Errors in radar precipitation data can be rangerelated effects, errors in the estimation of the relationship between rainfall rate $(R)$ and radarmeasured reflectivity $(Z)$, among others.

One approach to take into account the observation uncertainties of precipitation data is to probabilistically generate ensemble of precipitation fields using stochastic methods (Krajewski and Georgakakos, 1985). A popular class of stochastic methods is found within the framework of geostatistics (Vogel 2013). Geostatistical simulation methods preserve the mean value as well as the variance observed in the data. Additionally, they can also be applied within a conditional simulation 


\section{$6^{\text {TH }}$ INTERNATIONAL CONFERENCE ON FLOOD TIANAGETENT}

framework, which is a simulation that attempts to reproduce the entire random field while honoring the available data (Journel and Huijbregts, 1978; Bras and Rodriguez-Iturbe, 1993).

Among the available methods for the simulation of spatially correlated random fields, the turning bands method (TBM) has received attention in hydrologic applications (e.g., Ramos et al., 2006; Renard et al., 2011; Emmanuel et al, 2012; Leblois and Creutin, 2013). Simulations with the TBM search to characterize the uncertainty about the unsampled values of regionalized attributes (Emery and Lantuéjoul, 2006). It allows obtaining multidimensional simulations at a low computational cost.

The aim of this paper is to simulate space-time variable rainfall fields merging both information provided by rainfall radar and rain gauges. To achieve this objective, we used the adapted TBM method proposed by Leblois and Creutin (2013) and we propose the following new procedure: 1) applying the rainfall generator with parameters determined on radar rainfall fields, and 2) running conditional simulation that honors precipitation observed at rain gauges. A case study is presented using hydrometeorological data from the Var region (southeastern France), which is a region prone to flash flood events. Indeed, the Europe's Mediterranean region is frequently affected by this kind of events, which could be characterized by their very fast dynamics, and cause severe damage (Gaume et al.,2009, Naulin et al.,2013). For this feasibility study, results are presented just for one rainfall event observed in December 24th, 2009. In the following sections, we present the adapted TBM method, followed by its application to the 2009 flood rainfall event and a short discussion.

\section{TBM RAINFALL GENERATOR METHOD}

\subsection{Method presentation}

The conditional simulation method used here was based on the turning bands method (TBM) for stochastic generation of rainfall fields. This TBM-based rainfall generator is under development at IRSTEA and is described in details in Leblois and Creutin (2013). It was first applied to study longterm series of independent spatially distributed rain fields for space-time frequency analysis of extremes (Ramos et al., 2006). More recently, it was used within a conditional simulation framework to account for input data uncertainties in a flood forecasting chain (Renard et al., 2011).

The TBM method generates Gaussian random fields, which are then transformed to obtain the indicator field and the nonzero precipitation field (Leblois and Creutin, 2013). The TBM simulation depends on parameters describing the spatio-temporal properties of the observed rainfall fields (i.e., the variogram) and the at-site rainfall distribution. Further details about the generator used can be found in Leblois and Creutin (2013).

The originality of the present work is to combine the conditional simulation based on rain gauges only as operated by Renard et al (2011), with an estimation of the generator parameters made using rainfall radar fields as presented by Emmanuel et al (2012).

Parameters required by the TBM generator are: the space-time variogram range, the rainfall mean, the standard deviation of non-zero rainfalls, the percentage of zero rainfalls and the velocity.

As already explained in the introduction, for this study, these parameters will all be estimated for one particular event using radar pictures and rain gauges data representing the estimated cumulated rainfall at an hourly time step.

Results obtained for the estimation of these parameters are presented in section 4.2. 


\section{$6^{\text {TH }}$ INTERNATIONAL CONFERENCE ON FLOOD TIANAGETENT}

\section{DATA USED FOR THE ILLUSTRATIVE CASE STUDY}

Data used to illustrate the proposed method provide from the Var region in Southeastern France (Fig. 1). This area is prone to floods, able to cause huge damages, as occurred in June 2010 on the Argens watershed $\left(2500 \mathrm{~km}^{2}\right)$, where 25 casualties were reported (Javelle et al, 2014).

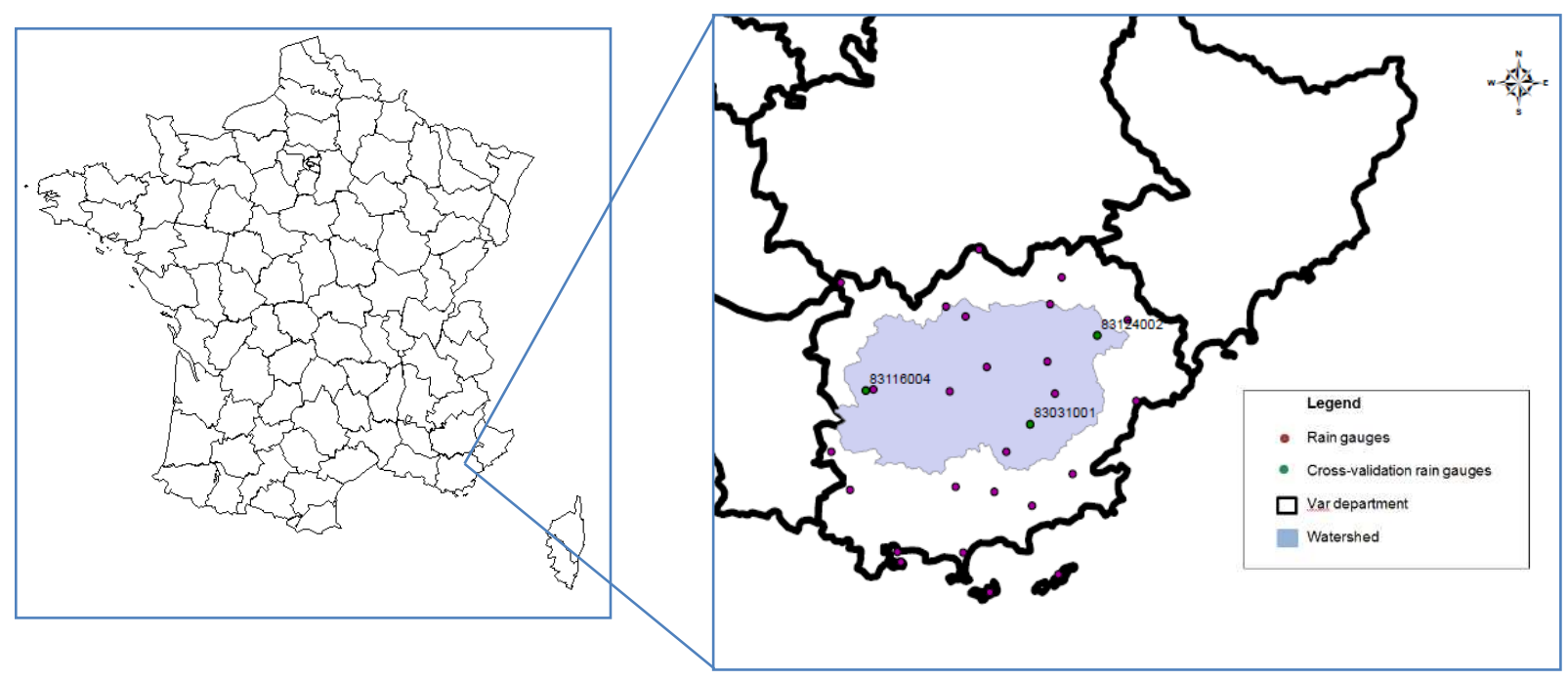

Figure1: Study area (department of VAR), with the Argens watershed and the location of the rain gauges used in this study (the red rain gauges were used for conditional simulation and the green rain gauges for cross-validation).

The event studied in the present work occurred on the December 24th, 2009. For this event, radar rainfall estimated was provided by Météo-France. The event lasted 9 hours, and used radar pictures are the hourly cumulated rainfall (so 9 pictures were used).

As illustrated by fig. 2, this event was chosen because it covers the entire areas, with significant rains (50 cumulated $\mathrm{mm}$ at some pixel, in 9 hours). Another reason (not shown here) is that a good adequacy between radar estimates and rain gauges is observed.

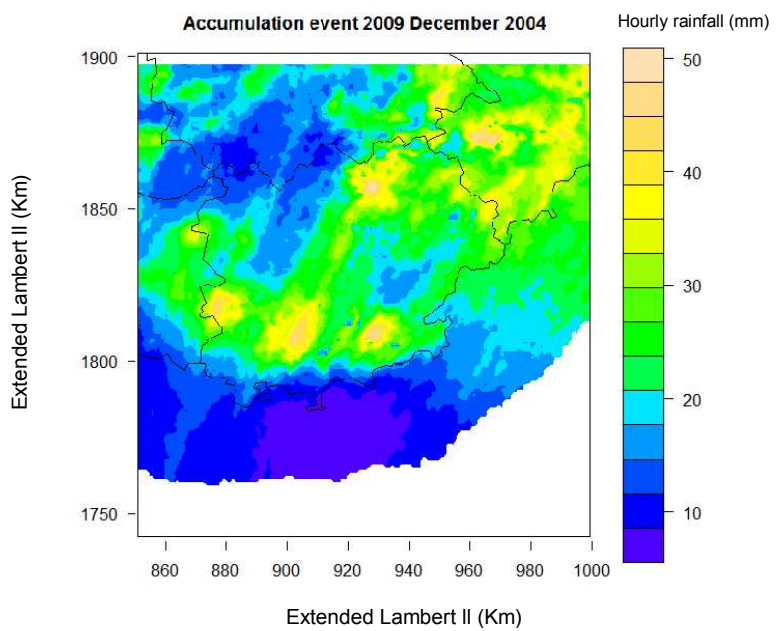

Figure 2: Total Precipitation from radar images for the event on December 24th, 2009 in the Var region. 


\section{$6^{\text {TH }}$ INTERNATIONAL CONFERENCE ON FLOOD TIANAGETENT}

26 rain gauges were used to estimate the parameters of the method, in red in Fig.1 (mean, the standard deviation of non-zero rainfalls and the percentage of zero rainfalls). The radar data were used to estimate the variogram and the at-site distribution of rainfall values. These rain gauges were also used to the at-site conditioning of the TBM simulation. Three rain gauges (in green in Fig.1), not used as conditioning data, were used to validate the ensemble of precipitation values generated by the TBM conditional simulation by comparison against observed (single-valued) precipitation measurements.

\section{RESULTS DOR THE DEC. $24^{\text {th }}, 2009$ FLOOD EVENT}

The application of the method presented in the previous sections was carried out using the data available for the December 24th, 2009 flood event.

\subsection{Estimated parameters of the rainfall field generator}

The rainfall process $w(x, t)$ is analyzed as a random process, $w$ being a rainfall intensity value, falling at the location $x$ and at time $t$. For the rainfall generator used in this study, we estimated the space and time variability (variograms) of non-zero rainfall fields and of the underlying intermittency (computed from indicator fields of rain/non-rain):

- Hourly radar data for the event period (2009/12/24 10:00 to 2009/12/24 18:00) were used to fit a exponential model on empirical variograms. The non-zero rainfall spatial and temporal variograms present a unique structure with ranges of $25 \mathrm{~km}$ and 6 hours, respectively. The spatial and temporal variograms of the rainfall intermittency have a structure with a range of $40 \mathrm{~km}$ in space and 9 hours in time.

- The mean, the standard deviation of non-zero rainfalls and the percentage of zero rainfalls were also estimated to define the at-site distribution. These were estimated using time series of hourly precipitation measurements at the 26 radar gauge stations represented in Fig. 1 for the event period (2009/12/24 10:00 to 2009/12/24 18:00). The values of the mean, standard deviation and the percentage of zeros obtained from the rain gauges are respectively: $10 \mathrm{~mm}, 4 \mathrm{~mm}$ and $16 \%$.

- In addition, the event velocity was also estimated. This one was estimated from the total duration of event divided by the total area of the studied region. The velocity used in this case was $5 \mathrm{~m} / \mathrm{s}$.

\subsection{Generated rainfall fields}

Once the rainfall generator is parameterized, conditional simulations were produced for the nine hours of the event on December 24th, 2009. All the simulations take into account the same parameters (estimated in 4.1) and are conditioned on the values of precipitation observed at the 26 rain gauges shown by red dots in Fig. 1. A total of 20 simulations were produced for each hourly time step. Fig. 3 presents 2 fields of the ensemble generated by the rainfall conditional simulator. It also shows the radar rainfall fields of the December 24th, 2009 event given by the radar database.

Based on Fig. 3, we can observe that, except at the rain gauge sites used for conditioning the simulations, the precipitation amounts from the ensemble of 20 generated fields are usually similar than the precipitation amounts given by the radar data, as the radar as the ensembles have the maximum value around $20 \mathrm{~mm} / \mathrm{h}$.

From Fig. 3, we can also see that, although the general advection of radar rain cells from southwest to northeast is well reproduced in the generated fields, the spatial extent of rainy areas in the simulated fields is usually shorter that in the radar field. This may also be explained by the fragmented vision of a rain field provided by the point measurements of rain gauges. 


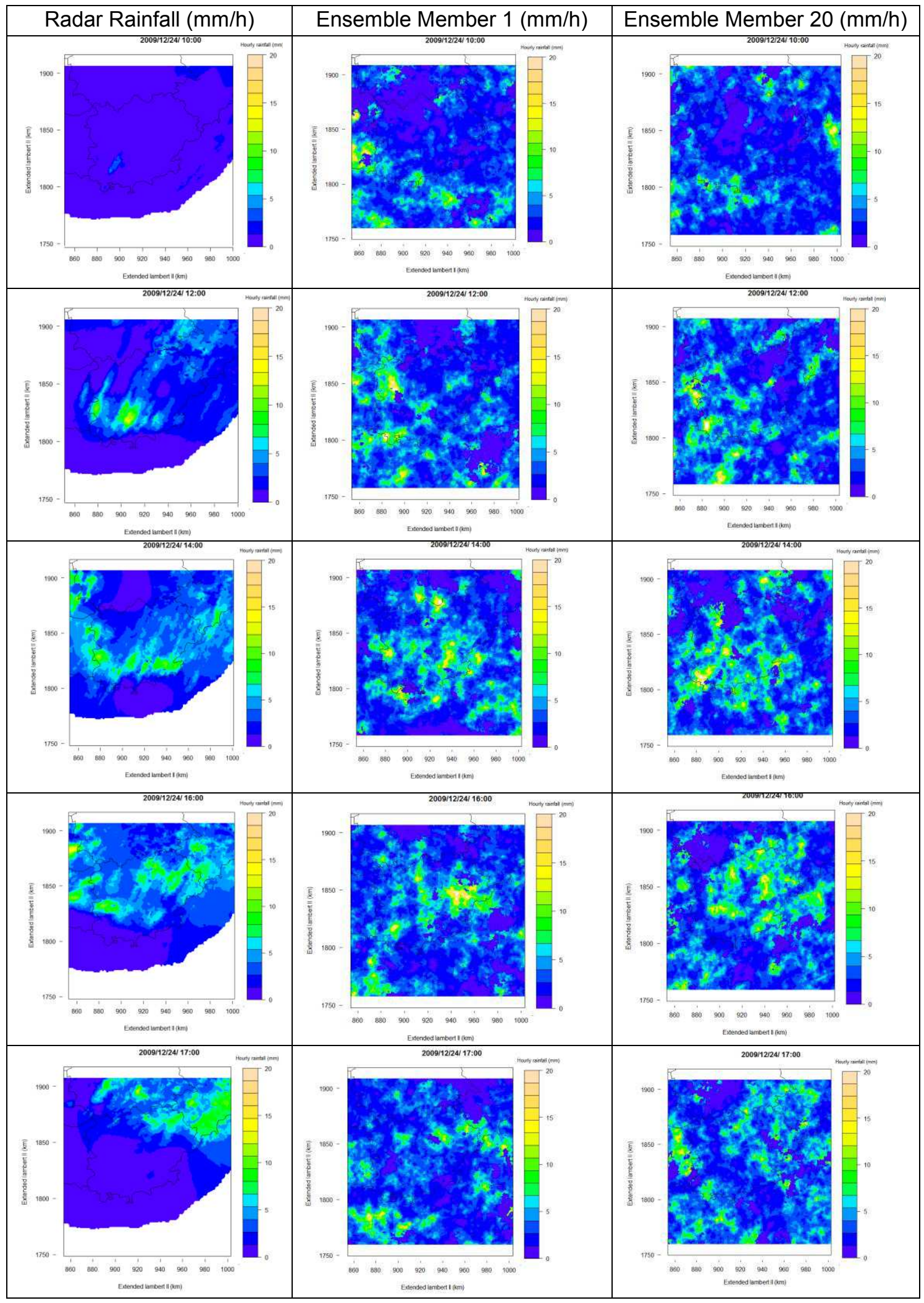

Figure 3: Illustration of the hourly rainfall fields from radar database (left) and from two members of the 20 -member ensemble of precipitation fields simulated by the rainfall generator used in this study (center and right). 


\section{$6^{\text {TH }}$ INTERNATIONAL CONFERENCE ON FLOOD IIANAGETENT}

\subsection{Ensemble validation}

In order to investigate further the performance of the rainfall generator, we compared the generated rain values with measurements at three rain gauge stations that were not used for the conditional simulation (stations represented by green dots in Fig. 1). They are thus used here as a one-step cross-validation method, usually applied to evaluate the performance of spatial interpolation methods (Isaaks and Srivastava, 1989). The fig. 4 and 5 show the comparison between the three rain gauges that were removed from the conditional simulation (three first bars in the X-axis) and the twenty members of the ensemble of precipitation fields generated in this study (named Ensemble 1 to 20 in the figures). The fig. 4 shows the amounts variability (box plot) of the ensembles and the rain gauges used to evaluate the performance of the rainfall generator. We can see that the rain given by the generated fields are similar to the rain gauges measures. The generator seems thus to represent well the variability around the at-site observed values.

The same feature is observed on Fig 5, which presents the same information but for the cumulated rainfall during the event.
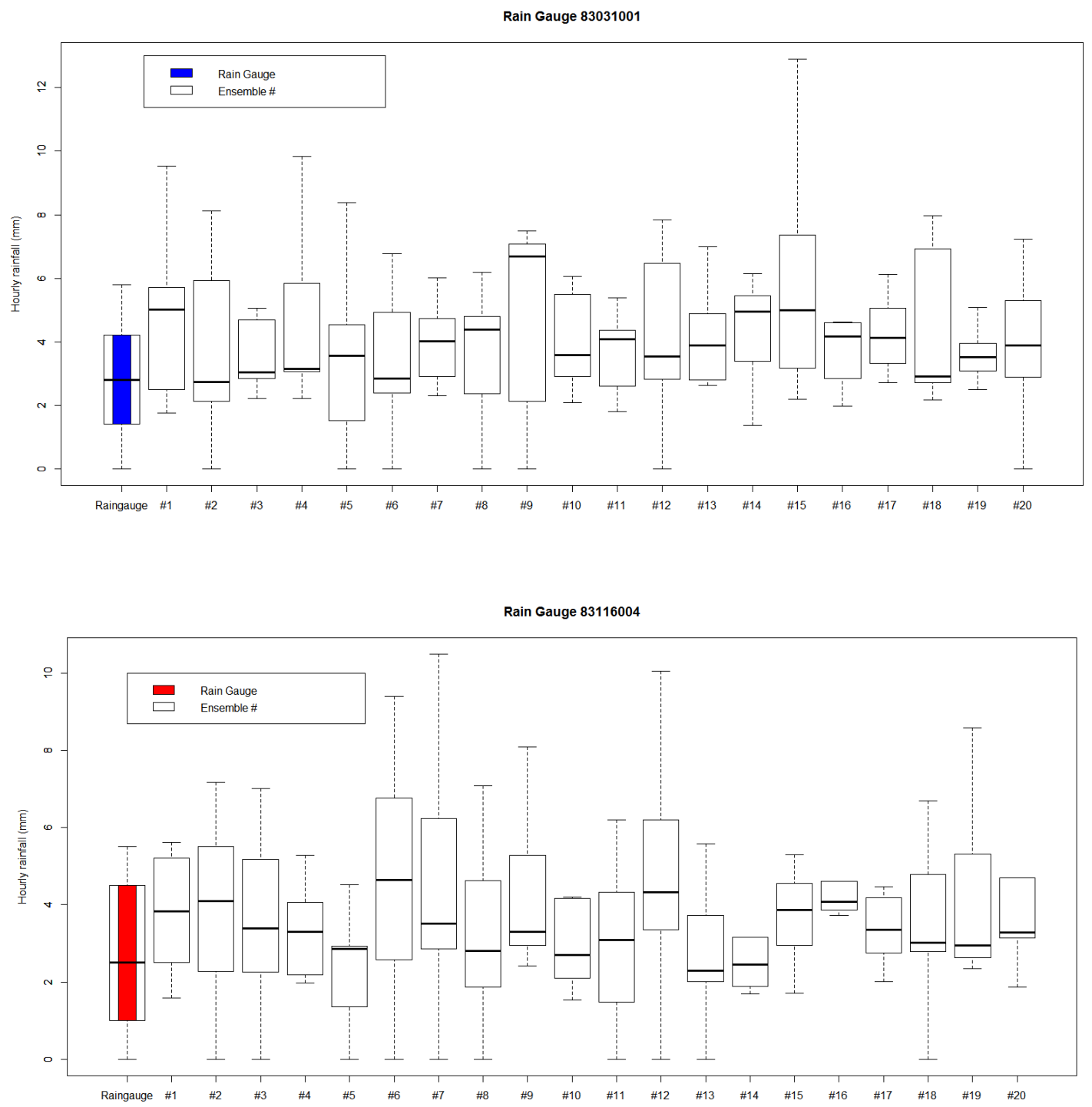


\section{$6^{\text {TH }}$ INTERNATIONAL CONFERENCE ON FLOOD TIANAGETENT}

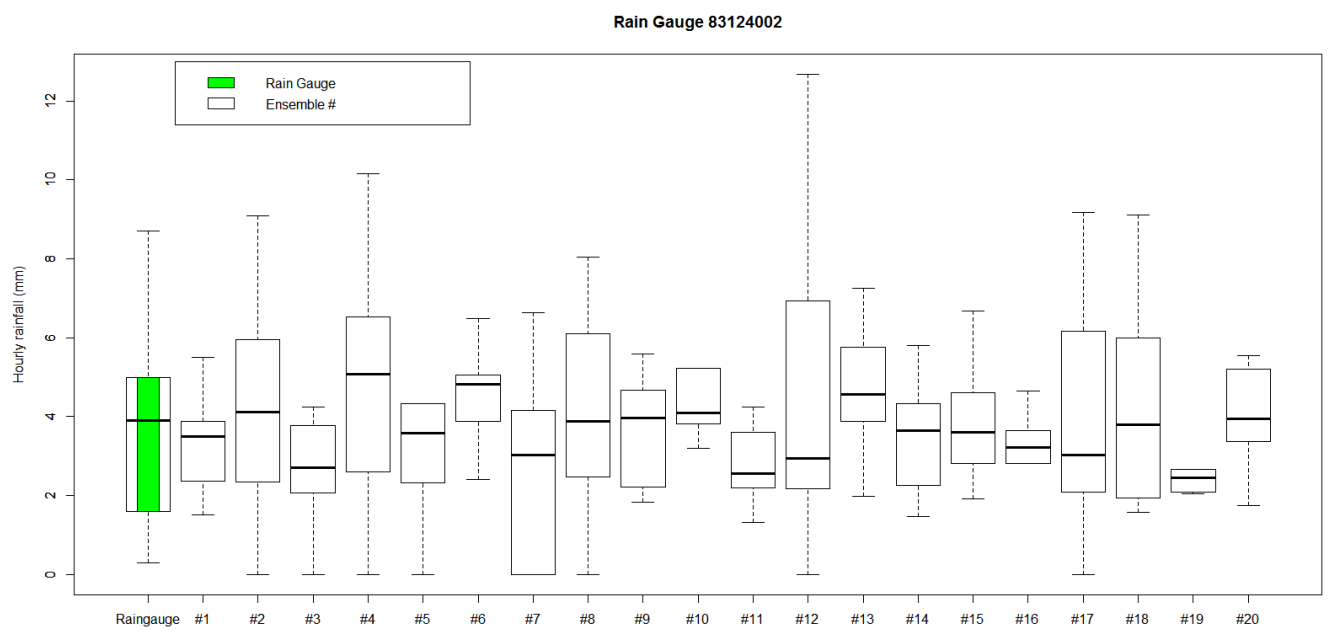

Figure 4: Box plots of the three rain gauges used for validation (not included in the conditioned simulation) and the 20 members of the ensemble of precipitation fields generated in this study.

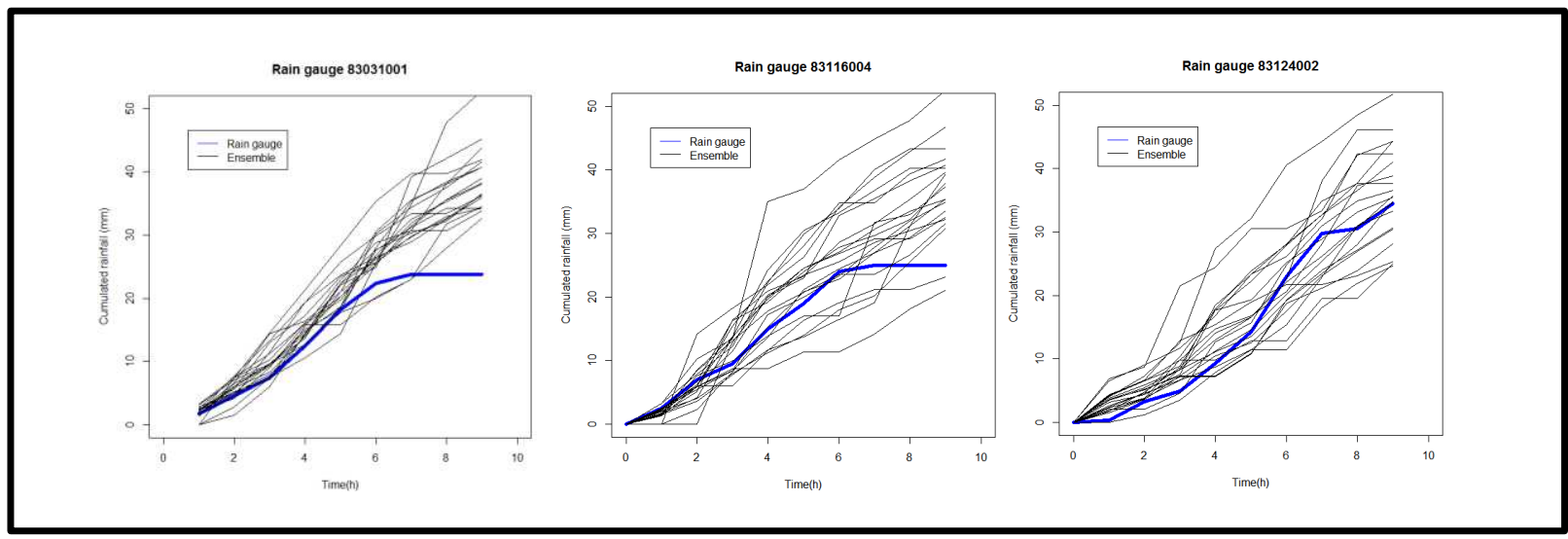

Figure 5: Cumulated rainfall amounts for three rain gauges used for validation (not included in the conditioned simulation) and for the 20 members of the ensemble of precipitation fields generated in this study. Rainfall is accumulated over the 9-hour duration of the December 24th, 2009 event.

\section{CONCLUSIONS}

In this study, we investigated a geostatistical technique to simulate precipitation fields and quantify observation uncertainties, based on radar and rain gauge precipitation data. The methodology was applied for one event located in the Var region in Southeastern France.

The research indicates the method feasibility. The rainfall generator is able to deliver an ensemble of rainfall fields that are consistent with the rain gauge measurements. From the analyses it can be seen that the ensembles amounts are quite similar that the radar data and that the rainfall generator takes into account the rain gauges measures.

Further investigations to improve the method here presented include better estimation of TBM parameters and validation across a larger number of events. 


\section{$6^{\text {TH }}$ INTERNATIONAL CONFERENCE ON FLOOD TIANAGETENT}

The ensembles generated by TBM will be used as input to a distributed hydrological model within the AIGA (Geographic information adaptation for flood warning) flood alert system. AIGA is a method developed by IRSTEA in collaboration with Météo-France (Javelle et al 2014).

\section{REFERENCES}

Berne, A., Krajewski, W.F., 2013. "Radar for hydrology: Unfulfilled promise or unrecognized potential?" Advances in Water Resources, 35th Year Anniversary Issue 51, 357-366.

Bras, R.L., Rodriguez-Iturbe, I., 1994. Random Functions and Hydrology. Dover Publications, New York.

Emmanuel, I., Andrieu, H., Leblois, E., Flahaut, B., 2012. "Temporal and spatial variability of rainfall at the urban hydrological scale." Journal of Hydrology 430-431, 162-172.

Gaume, E., Bain, V., Bernardara, P., Newinger, O., Barbuc, M., Bateman, A., Blaškovičová, L., Blöschl, G., Borga, M., Dumitrescu, A., Daliakopoulos, I., Garcia, J., Irimescu, A., Kohnova, S., Koutroulis, A., Marchi, L., Matreata, S., Medina, V., Preciso, E., Sempere-Torres, D., Stancalie, G., Szolgay, J., Tsanis, I., Velasco, D., Viglione, A., 2009. "A compilation of data on European flash floods." Journal of Hydrology 367, 70-78.

Isaaks, E.H., Srivastava, R.M., 1990. An Introduction to Applied Geostatistics. Oxford University Press, New York.

Javelle, P., Demargne, J., Defrance, D., Pansu, J., Arnaud, P., 2013. "Evaluating flash flood warnings at ungauged locations using post-event survey: a case study with the AIGA warning system." Hydrological Sciences Journal/Journal des Sciences Hydrologiques.

Journel, A.G., Huijbregts, C.J., 2004. Mining Geostatistics. The Blackburn Press, Caldwell, N.J.

Krajewski, W.F. and Georgakakos, K.P., 1985. "Synthesis of Radar Rainfall Data". Water Resources Research, 21(5): 764-768.

Leblois, E., Creutin, J.-D., 2013. "Space-time simulation of intermittent rainfall with prescribed advection field: Adaptation of the turning band method." Water Resour. Res. 49, 3375-3387.

Liechti, K., Panziera, L., Germann, U., Zappa, M., 2013. "The potential of radar-based ensemble forecasts for flash-flood early warning in the southern Swiss Alps." Hydrol. Earth Syst. Sci. 17, 3853-3869.

Naulin, J.-P., Payrastre, O., Gaume, E., 2013. "Spatially distributed flood forecasting in flash flood prone areas: Application to road network supervision in Southern France." Journal of Hydrology 486,

Ramos, M.H., Leblois, E., Creutin, J.-D., 2006. "From point to areal rainfall: linking the different approaches for the frequency characterisation of rainfalls in urban areas." Water Science \& Technology 54, 33.

Renard, B., Kavetski, D., Leblois, E., Thyer, M., Kuczera, G., Franks, S.W., 2011. "Toward a reliable decomposition of predictive uncertainty in hydrological modeling: Characterizing rainfall errors using conditional simulation." Water Resour. Res. 47, W11516.

Uijlenhoet, R., Berne, A., 2008. "Stochastic simulation experiment to assess radar rainfall retrieval uncertainties associated with attenuation and its correction." Hydrol. Earth Syst. Sci. 12, 587601. 
Vogel, R., Klimatologie, S.B. für M. und, 2013. "Quantifying the Uncertainty of Spatial Precipitation Analyses with Radar-gauge Observation Ensembles." Bundesamt für Meteorologie und Klimatologie, MeteoSchweiz. 